\title{
A workshop on Gentle Teaching
}

\author{
J. Piachaud
}

Gentle Teaching (McGee et al, 1987) has been described as a technique for working with people who have learning disabilities and severe behavioural disorders. I attended a two-day workshop from 25-27 May 1994 run by the Royal College of Nursing, Bexley MENCAP and Values Incorporated.

With facilitators Dan Hobbs, Simon Goldsmith and Brigitte Bygrave, 26 people including parents, doctors, nurses, social workers, psychologists and care staff gathered for what was a valuable experience.

The term Gentle Teaching arose from the view that aversive techniques and regimes of punishment were inappropriate and ineffective strategies for responding to the needs of disabled people. The theory underlying the workshop was that behavioural problems should be seen within the context of relationships and that positive social interactions come about when people positively value each other.

This approach did not appear to deny illness nor did it deny the difficulty of working with some people or the long-term nature of some problems. It included a number of tried and tested teaching techniques such as fading, shaping, modelling, with involvement in carefully planned and monitored activities. There was also use of cognitive approaches and psychotherapeutic concepts such as engagement and a recognition of unexpressed emotional lives. The most powerful tool for change was seen as introducing positive values into our relationships with clients regardless of their actions, bringing commitment and empathy, judging behaviours not people.

It was accepted that physical safety is paramount and that this may involve physical interventions to create security and prevent physical injury. There was criticism of punishment techniques and of outside professionals who wrote impersonal reports of an impractical nature. Expectations of staff were high and models of staff support were discussed.

Several participants had brought videos of their work and we commented on their approach, their verbal and non-verbal communications, how they operated in group settings, the value of tasks and ways in which people were engaged into tasks. We shared other experiences of work, things which had been successful and things that had failed.

The workshop raises issues of training. How many of us give advice in residential homes without ever having worked in one? We should ensure that one training objective is experience of working in a residential home, another being the use of video in residential settings.

Gentle Teaching was perhaps not so much new as refreshing; I was impressed both by a process of analysis and strategy for dealing with people who present very difficult problems and by the commitment of the workshop members.

If Gentle Teaching is to acquire a more precise meaning then it must be rigorous in its definitions and subject itself to scientific evaluation otherwise I suspect the phrase will continue in use as a general expression of an interactive humane approach which asks that we look at values as well as actions.

\section{Reference}

McGee, J., Menolascino, F., Hobbs, D. \& Menousek, P. (1987) Gentle Teaching: $a$ non-aversive approach to helping persons with mental retardation. New York: Human Sciences Press.

J. Piachaud, Consultant Psychiatrist, St Charles' Hospital, London W10 6DZ 